Original Article

\title{
Crack propagation speed in ceramic during quenching
}

\author{
Yingfeng Shao ${ }^{\mathrm{a}, \mathrm{c}, *}$, Boyang Liu ${ }^{\mathrm{b}}$, Xiaohuan Wang ${ }^{\mathrm{a}, \mathrm{c}}$, Long $\mathrm{Li}^{\mathrm{a}, \mathrm{c}}$, Jiachen Wei ${ }^{\mathrm{a}, \mathrm{c}}$, Fan Song ${ }^{\mathrm{a}, \mathrm{c}}$ \\ a State Key Laboratory of Nonlinear Mechanics, Institute of Mechanics, Chinese Academy of Sciences, Beijing 100190, China \\ ${ }^{\mathrm{b}}$ College of Ocean Science and Engineering, Shanghai Maritime University, Shanghai 201306, China \\ ${ }^{\mathrm{c}}$ School of Engineering Science, University of Chinese Academy of Sciences, Beijing 100049, China
}

\section{A R T I C L E I N F O}

\section{Keywords:}

Ceramic

Thermal shock

Crack speed

Numerical simulation

Real-time

\begin{abstract}
A B S T R A C T
The effects of water quenching temperature and specimen size on the propagation speed of thermal shock crack are investigated in real time by water quenching of translucent ceramic and high-speed imaging. The results show that the crack growth rate increases with the increase of quenching temperature difference or specimen size. Within $100 \mathrm{~ms}$, average crack speed is $20.3 \mathrm{~mm} / \mathrm{s}$ at a temperature difference of $400^{\circ} \mathrm{C}$ in $20 \mathrm{~mm}$ wide ceramic and is $11.9 \mathrm{~mm} / \mathrm{s}$ at a temperature difference of $220^{\circ} \mathrm{C}$ in $5 \mathrm{~mm}$ wide ceramic, respectively. Compare with specimen size, the influence of quenching temperature difference on the crack propagation speed is larger. The calculations based on meso-damage mechanics have similar results to those of experiments. This paper quantitatively studies the thermal-shock crack growth of ceramic in real time and expands the scientific understanding of thermal shock cracking phenomenon of ceramic.
\end{abstract}

\section{Introduction}

Ceramic is prone to crack under severe thermal shock condition because of its inherent brittleness [1], and its mechanical properties will be greatly damaged by cracks [2]. As a result, more than one-third of the rejections of ceramic components are caused by thermal shock [3]. Therefore, the determination of thermal shock cracking for ceramic is always required for engineering applications.

Numerous theoretical studies on thermal shock crack propagation and crack length hierarchy phenomena have been reported, including the principle of energy [4], the energy release rate [5], the energy minimization [6,7], the non-local failure model [8], the meso-damage mechanics [9], and the variational model etc $[10,11]$. These works verified and complemented to each other, much promoted the studies on thermal shock cracking phenomenon of ceramic. However, all theoretical models are only proved by the final results of the tests, rather than the whole process. So, there is still a challenge for quantitative study on the process of cracking. To overcome this difficulty and to bridge the gap between theoretical prediction and experimental data, we developed a real-time observation of thermal shock cracking method [12], where the crack propagation is successfully captured, and the crack growth rate is calculated from the images. The goal of this paper is to find a theoretical method which can be utilized to predict the thermal-shock crack growth of ceramic.

For this purpose, we experimentally reveal the crack propagation speed of the semi-transparent ceramic sheet during the real-time thermal shock process. By comparing the crack growth rate with the numerical result based on meso-damage mechanics, we verify the feasibility of this method. In addition, we further point out the influence of quenching temperature difference and specimen size on the propagation speed of thermal shock crack.

\section{Experimental procedure}

\subsection{Materials processing}

The translucent ceramic was made of high purity $99.5 \% \mathrm{Al}_{2} \mathrm{O}_{3}$ powder (particle size $0.5 \mu \mathrm{m}$; Xiongdi Material Co., Ltd., Jiyuan, China), which was tape casting and subsequently sintered at $1850^{\circ} \mathrm{C}$ for $2 \mathrm{~h}$ in hydrogen. The bulk density of the ceramic was about $3.96 \mathrm{~g} / \mathrm{cm}^{3}$ by measuring its dimension and weight. The mean grain size at the surface was about $18.9 \mu \mathrm{m}$ by using the mean linear intercept method.

\subsection{Thermal shock test}

To ensure the formation of a two-dimensional penetrating crack, ceramic sheets with dimensions of $0.4 \mathrm{~mm}$ in thickness, 5,10 or $20 \mathrm{~mm}$ in width, and $50 \mathrm{~mm}$ in length were employed to investigate the crack patterns during water quenching. To prevent access of the coolant to the side faces, the sheet was stacked with two quartz glass slabs and was bound up with inconel wires, as shown in Fig. 1. The specimen was heated to a preset temperature at a rate of $10^{\circ} \mathrm{C} / \mathrm{min}$ and held for

\footnotetext{
* Corresponding author at: State Key Laboratory of Nonlinear Mechanics, Institute of Mechanics, Chinese Academy of Sciences, Beijing 100190, China.

E-mail address: shaoyf@lnm.imech.ac.cn (Y. Shao).
} 


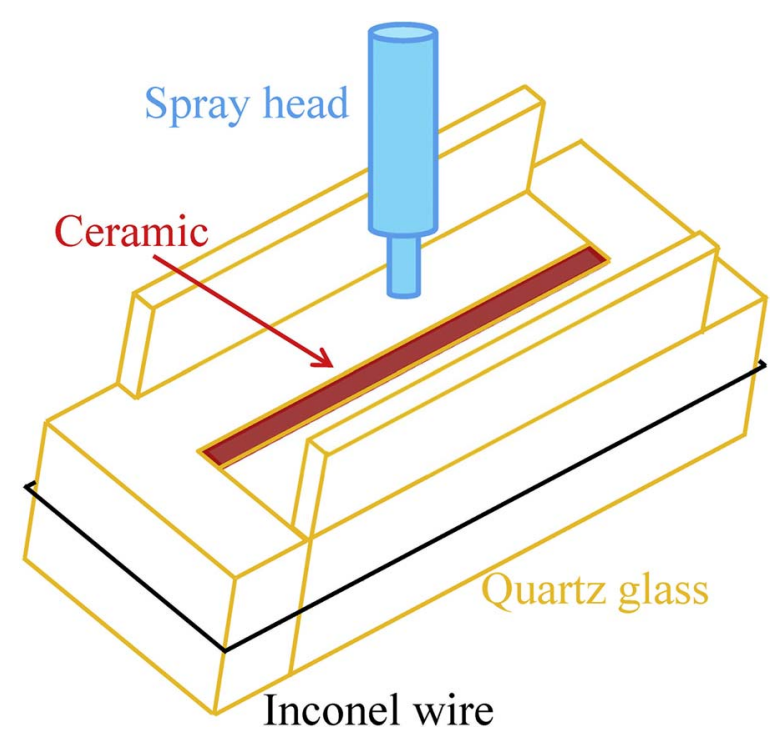

Fig. 1. Relative position of stacked sample and spray head for thermal shock.

$30 \mathrm{~min}$. After that, the sample was quickly taken out and put in a prefocused position on a table within $5 \mathrm{~s}$, then the spray head upon the sample began to spray deionized water of $20^{\circ} \mathrm{C}$ at a rate of about $5 \mathrm{ml} / \mathrm{s}$. Water flowed through the flume on quartz slabs, so the test sheet with the narrow upper surface $(0.4 \mathrm{~mm} \times 50 \mathrm{~mm})$ was subjected to water quenching. The high-speed camera (Fastcam SA-X2, Photron, Tokyo, Japan) was used to capture images during the thermal shock process at 10,000 frames per second with a resolution of $1024 \times 512$ Pixels. From the series of recorded images, the crack speed could be obtained by the slope of the crack length curves per millisecond. The details are given elsewhere [12].

\section{Numerical simulations}

Here we use meso-damage mechanics to calculate the extent of crack growth. The FEM is used to evaluate the temperature and stress distribution in the specimen during water quenching. In the simulation, a statistical model of a heterogeneous elastic-brittle medium is used, and the damage criterion is used to check whether the elements fail or not.

\subsection{Finite element model for temperature and stress simulation}

A 2D plane stress FE model is introduced to depict the above water quenching test of ceramic sheet, along with the appropriate boundary conditions. In the beginning, a ceramic sheet with a uniform initial temperature $T_{0}$ is suddenly exposed to water with a uniform temperature $T_{\infty}$, as shown in Fig. 2a.
The specimen dimensions are $L=50 \mathrm{~mm}$ along the $\mathrm{X}$-axis, and $H=5,10$ or $20 \mathrm{~mm}$ along the $\mathrm{Y}$-axis, respectively. The right $1 / 2$ area of the specimen is shown in Fig. 2a, the length of the finite element is $0.05 \mathrm{~mm}$ and the size of the time increment is $t=0.5 \mathrm{~ms}$. The input parameters of alumina used in the calculation are listed in Table 1. It is assumed that the presence of the cracks that have formed do not influence the temperature distribution in the sheet under quenching, which can easily be calculated by Fourier's law of heat conduction. Then, the strain and stress distributions within the body are calculated from the temperature distribution at any given time by thermo-elastic theory, as well as strain energy density.

\subsection{Mesoscopic heterogeneity of ceramics}

According to experimental results, the statistic of fractures in ceramics follows Weibull distribution [3]. Therefore, in the presented numerical model, both strength and elastic modulus of ceramic are assumed to follow a Weibull distribution, whose probability density function is given as [9]:

$f(\sigma)=\frac{m}{\zeta_{0}} \cdot\left(\frac{\zeta}{\zeta_{0}}\right)^{m-1} \cdot \exp \left[-\left(\frac{\zeta}{\zeta_{0}}\right)^{m}\right]$

where $\zeta$ is the strength or elastic modulus of the element, $\zeta_{0}$ is the initial strength or elastic modulus of materials, and $m$ is the shape parameter or Weibull modulus which is set to be 15 [9]. In addition, the strength and elastic modulus of each element are considered as [9]:

$\zeta_{i}=\zeta_{0}\left(-\ln \omega_{i}\right)^{1 / m}, i=1 \ldots \mathrm{N}$

Where $\zeta_{i}$ is the strength/elastic modulus of the element $i . \omega$ is a random distributed number ranging from 0 to 1 .

\subsection{Meso-damage evolution}

Continuum damage mechanics is used to describe the mechanical behavior of mesoscopic elements in the brittle material. Only tensile stress is considered in this study because most of the thermal shock failures occur in the tensile mode. The relation can be expressed as

$\sigma_{\mathrm{T}}(i, t)=[1-D(i, t)] E(i, 0) \varepsilon_{\mathrm{T}}(i, t)$

where $\sigma_{\mathrm{T}}(i, t), \varepsilon_{\mathrm{T}}(i, t)$ and $D(i, t)$ are the equivalent tensile stress, equivalent tensile strain and damage variable of the ith mesoscopic element under tensile mode. $E(i, 0)$ is the initial elastic modulus. The stiffness of elements degrades gradually as damage progresses, and the elastic modulus of the $i$ th damaged mesoscopic element can be defined as follows

$E(i, t)=[1-D(i, t)] E(i, 0)$

As the ith mesoscopic element is in the damage mode, the damage evolution equation can be expressed as (Fig. 2b)
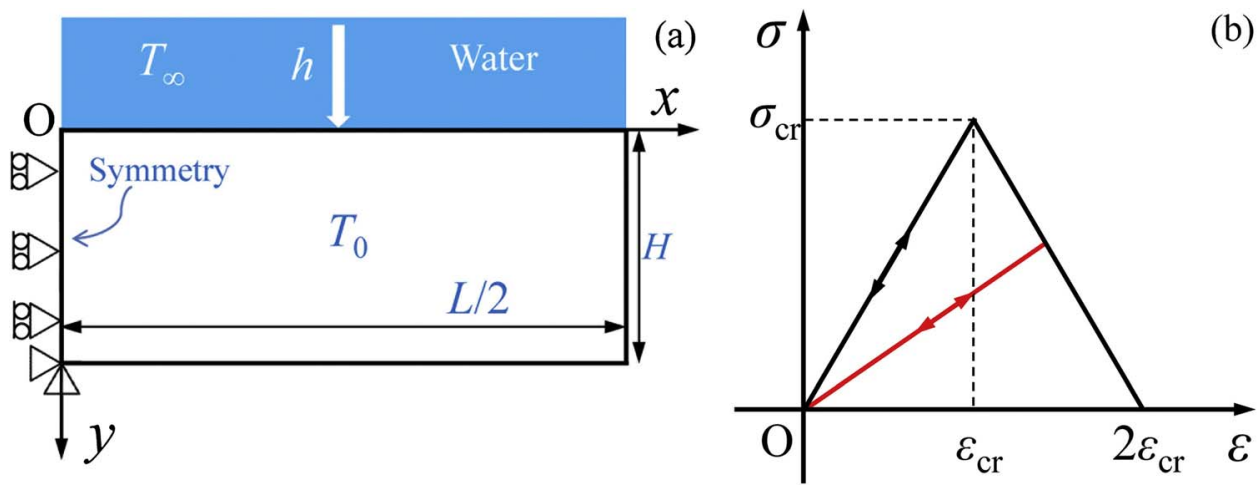

Fig. 2. (a) Finite element model used to determine the temperature and stress distribution in the specimen, (b) Damage constitutive model of the mesoscopic element. 
Table 1

Mechanical and thermal parameters of alumina used in calculation.

\begin{tabular}{|c|c|c|c|c|c|c|}
\hline $\begin{array}{l}\text { Young modulus } E \\
(\mathrm{GPa})\end{array}$ & Poisson's ratio $\nu$ & $\begin{array}{l}\text { Strength } \sigma_{0} \\
(\mathrm{MPa})\end{array}$ & $\begin{array}{l}\text { Convective heat transfer } \\
\text { coefficient } h\left(\mathrm{~W} \mathrm{~m}^{-2} \mathrm{~K}^{-1}\right)\end{array}$ & $\begin{array}{l}\text { Thermal conductivity } k \\
\left(\mathrm{~W} \mathrm{~m} \mathrm{~m}^{-1} \mathrm{~K}^{-1}\right)\end{array}$ & $\begin{array}{l}\text { Coefficient of thermal } \\
\text { expansion } \alpha\left(10^{-6} \mathrm{~K}^{-1}\right)\end{array}$ & $\begin{array}{l}\text { Specific heat } \mathrm{c}(\mathrm{J} / \\
\mathrm{kg} \mathrm{K})\end{array}$ \\
\hline 370 & 0.22 & 200 & 40000 & 20 & 6.8 & 880 \\
\hline
\end{tabular}
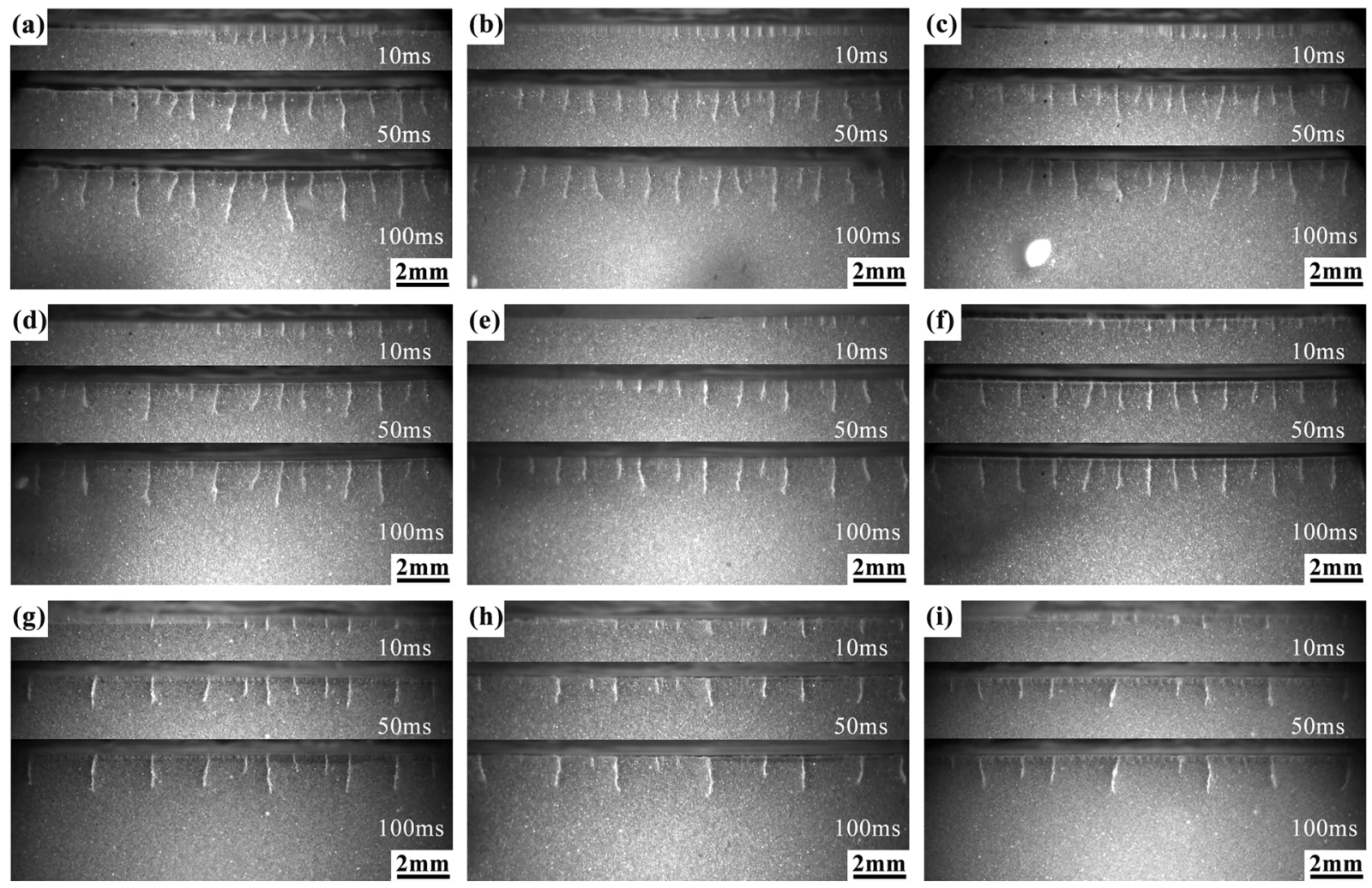

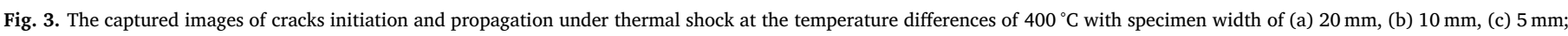
$300{ }^{\circ} \mathrm{C}$ with specimen width of (d) $20 \mathrm{~mm}$, (e) $10 \mathrm{~mm}$, (f) $5 \mathrm{~mm}$; and $220^{\circ} \mathrm{C}$ with specimen width of (g) $20 \mathrm{~mm}$, (h) $10 \mathrm{~mm}$, (i) $5 \mathrm{~mm}$.

Table 2

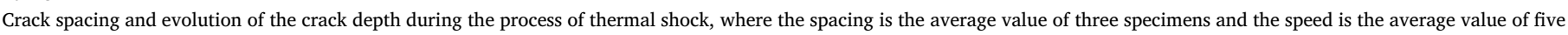
cracks.

\begin{tabular}{|c|c|c|c|c|c|c|c|c|c|}
\hline$\Delta T\left({ }^{\circ} \mathrm{C}\right)$ & & 220 & & & 300 & & & 400 & \\
\hline Width (mm) & 5 & 10 & 20 & 5 & 10 & 20 & 5 & 10 & 20 \\
\hline Average crack spacing $(\mathrm{mm})$ & $1.57 \pm 0.16$ & $1.52 \pm 0.11$ & $1.52 \pm 0.14$ & $1.09 \pm 0.09$ & $1.04 \pm 0.07$ & $1.11 \pm 0.08$ & $0.80 \pm 0.04$ & $0.76 \pm 0.07$ & $0.76 \pm 0.03$ \\
\hline Calculated value (mm) & $1.62 \pm 0.09$ & $1.57 \pm 0.09$ & $1.52 \pm 0.14$ & $1.14 \pm 0.05$ & $1.14 \pm 0.09$ & $1.11 \pm 0.08$ & $0.78 \pm 0.02$ & $0.78 \pm 0.04$ & $0.76 \pm 0.07$ \\
\hline Average crack speed $(\mathrm{mm} / \mathrm{s}, 1 \mathrm{~ms})$ & $143 \pm 14$ & $158 \pm 16$ & $168 \pm 15$ & $164 \pm 16$ & $164 \pm 18$ & $181 \pm 17$ & $202 \pm 19$ & $246 \pm 22$ & $207 \pm 23$ \\
\hline Average crack speed $(\mathrm{mm} / \mathrm{s}, 50 \mathrm{~ms})$ & $19.1 \pm 1.8$ & $20.5 \pm 2.1$ & $25.4 \pm 2.4$ & $21.0 \pm 2.2$ & $24.0 \pm 2.3$ & $25.8 \pm 2.6$ & $25.3 \pm 2.5$ & $25.9 \pm 2.5$ & $29.1 \pm 2.8$ \\
\hline Average crack speed $(\mathrm{mm} / \mathrm{s}, 100 \mathrm{~ms})$ & $11.9 \pm 0.9$ & $13.7 \pm 1.2$ & $15.0 \pm 1.4$ & $14.1 \pm 1.3$ & $15.3 \pm 1.2$ & $17.6 \pm 1.4$ & $16.4 \pm 1.5$ & $17.3 \pm 1.6$ & $20.3 \pm 1.8$ \\
\hline Calculated value $(\mathrm{mm} / \mathrm{s}, 100 \mathrm{~ms})$ & $13.0 \pm 1.0$ & $14.2 \pm 0.9$ & $16.1 \pm 1.3$ & $13.2 \pm 1.4$ & $16.3 \pm 1.3$ & $17.2 \pm 1.5$ & $15.9 \pm 1.6$ & $18.9 \pm 1.5$ & $20.7 \pm 1.7$ \\
\hline
\end{tabular}

$D(i, t)=\left\{\begin{array}{cl}0 & 0 \leq \varepsilon_{\mathrm{T}}(i, t) \leq \varepsilon_{\mathrm{cr}}(i) \\ \frac{\varepsilon \mathrm{T}(i, t)-2 \varepsilon_{\mathrm{cr}}(i)^{2}}{2 \varepsilon_{\mathrm{cr}}(i)-\varepsilon_{\mathrm{cr}}(i) \times \varepsilon_{\mathrm{T}}(i, t)} & \varepsilon_{\mathrm{cr}}(i) \leq \varepsilon_{\mathrm{T}}(i, t) \leq 2 \varepsilon_{\mathrm{cr}}(i) \\ 1 & \varepsilon_{\mathrm{T}}(i, t) \geq 2 \varepsilon_{\mathrm{cr}}(i)\end{array}\right.$

where $\varepsilon_{\mathrm{cr}}(i)=\sigma_{\mathrm{cr}}(i) / E(i, 0)$ is the critical tensile strain of the $i$ th unit at the elastic limit, and $2 \varepsilon_{\mathrm{cr}}(i)$ is the ultimate strain, describing the state in which the element is completely damaged. The equivalent tensile strain $\varepsilon_{\mathrm{T}}(i, t)$ can be expressed by

$\varepsilon_{\mathrm{T}}(i, t)=\sqrt{\left\langle\varepsilon_{1}(i, t)\right\rangle^{2}+\left\langle\varepsilon_{2}(i, t)\right\rangle^{2}}$

Where $\varepsilon_{1}$ and $\varepsilon_{2}$ are two principal strains of the mesoscopic element, and the operator $<>$ is a function defined as $\langle x\rangle= \begin{cases}x, & x \geq 0 \\ 0, & x<0\end{cases}$

\section{Results and discussion}

The captured images of ceramic crack initiation and propagation under thermal shock at quenching temperature difference $\Delta T$ of $220^{\circ} \mathrm{C}$, $300{ }^{\circ} \mathrm{C}$ and $400{ }^{\circ} \mathrm{C}$, are shown in Fig. 3. It suggests that the crack initiation and propagation processes are more or less similar among the specimens with different $\Delta T$, and the difference is the number of the cracks increases with the increase of $\Delta T$. In detail, at $100 \mathrm{~ms}$, when $\Delta T=220^{\circ} \mathrm{C}$, there are only sparse cracks on the surface of the sheets; when $\Delta T=400^{\circ} \mathrm{C}$, a hierarchical structure of short and long cracks 

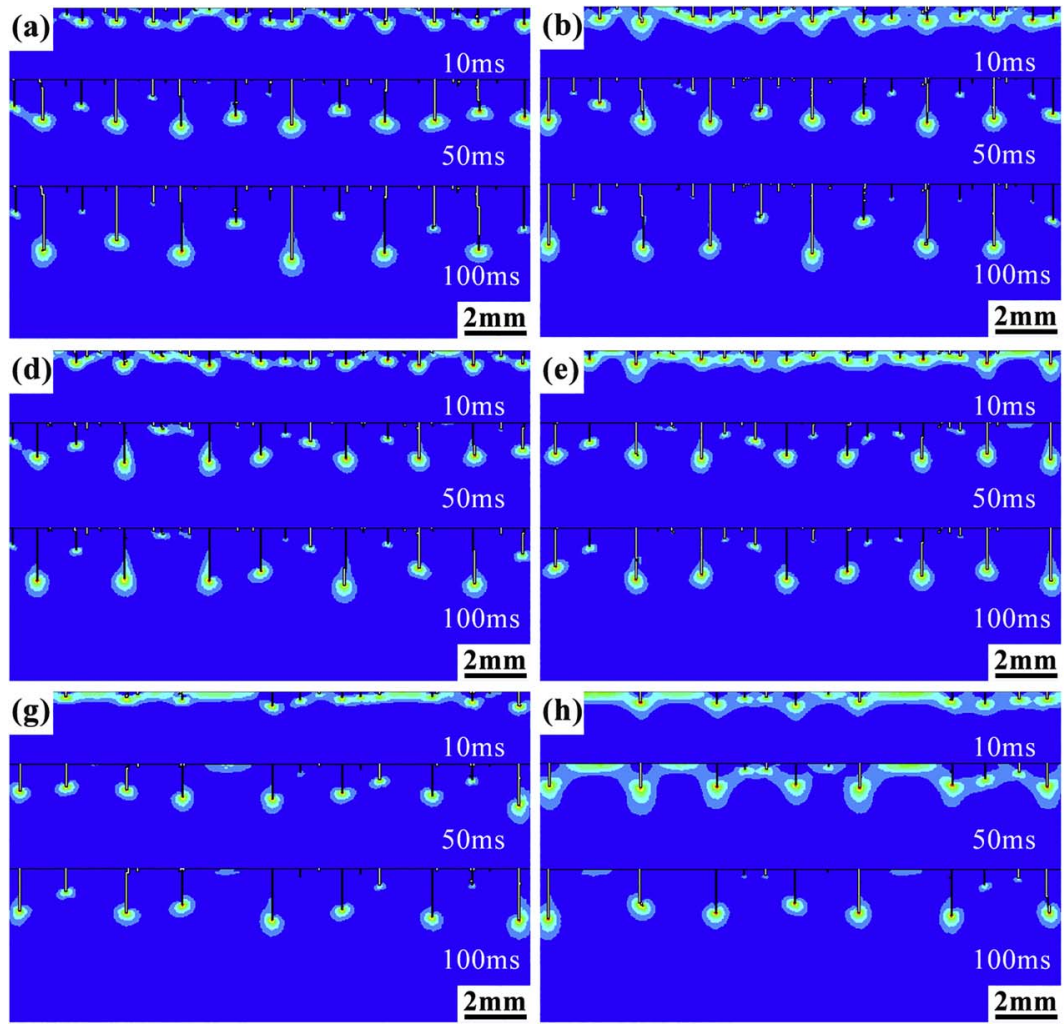
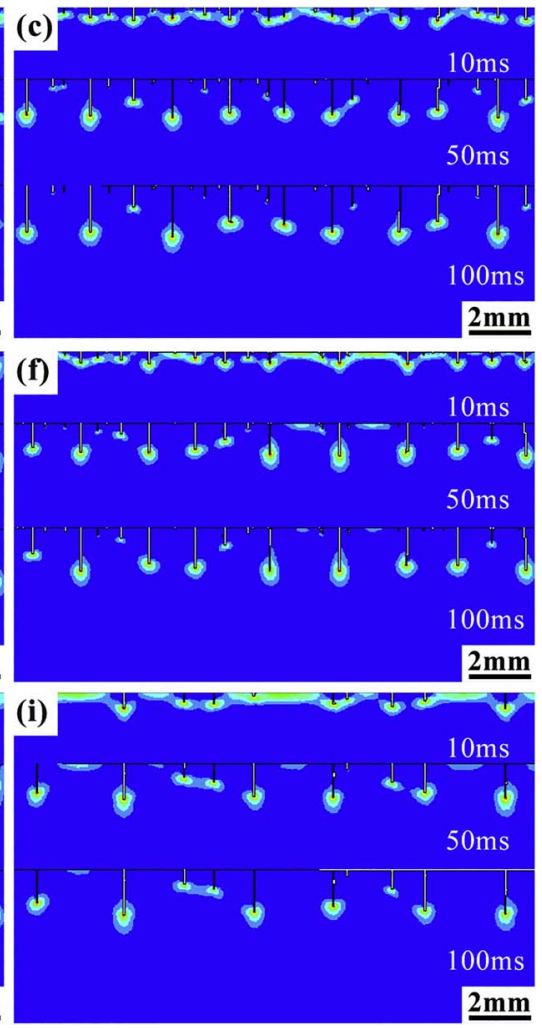

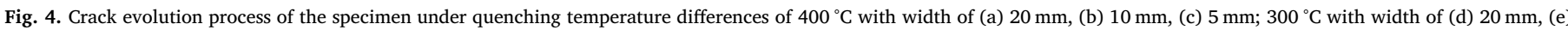
$10 \mathrm{~mm}$, (f) $5 \mathrm{~mm}$; and $220^{\circ} \mathrm{C}$ with width of (g) $20 \mathrm{~mm}$, (h) $10 \mathrm{~mm}$, (i) $5 \mathrm{~mm}$ by numerical simulation.
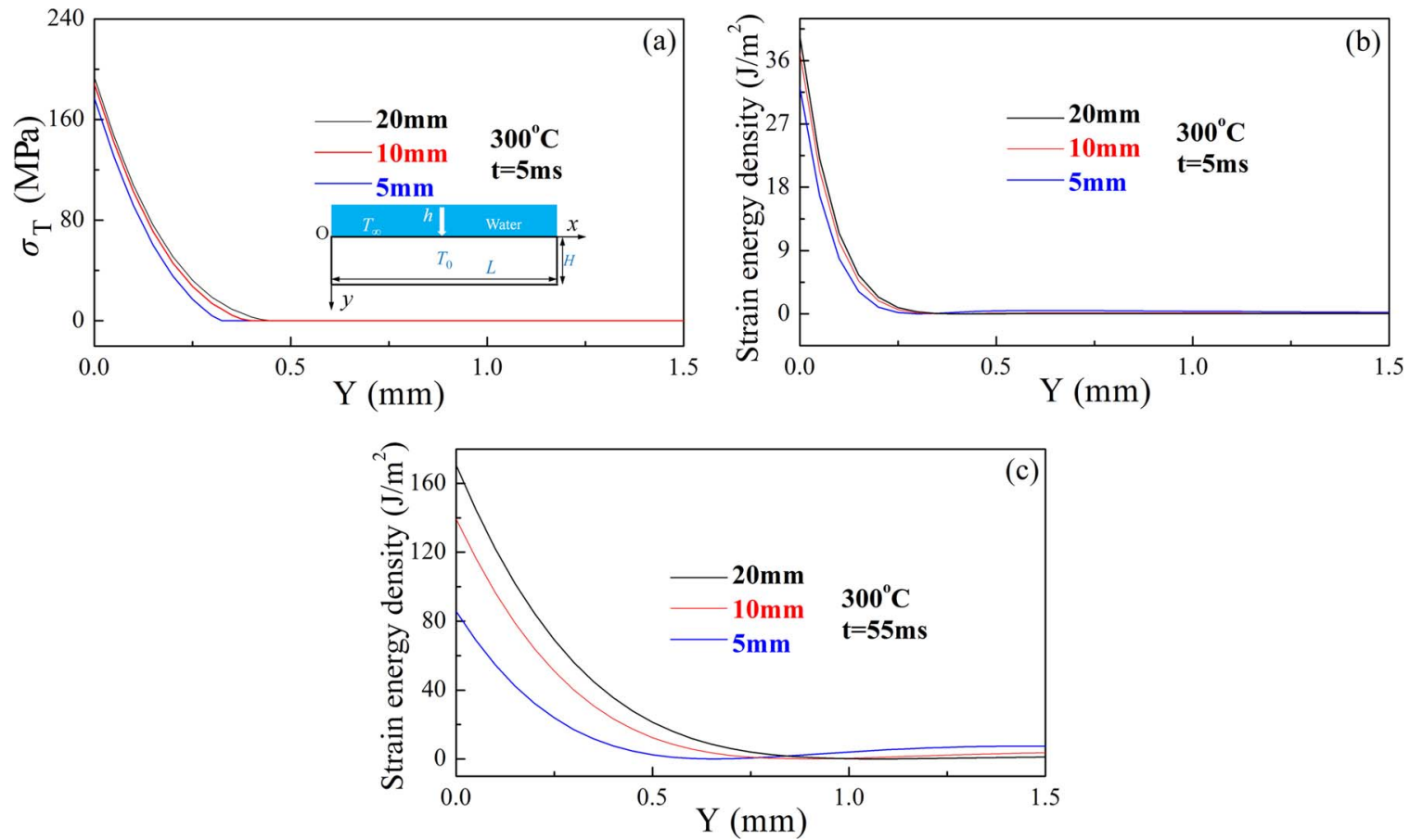

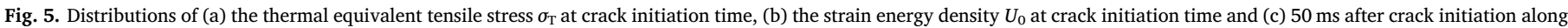
$y$-direction for various wide ceramics at $T_{0}=300{ }^{\circ} \mathrm{C}$

becomes more pronounced, which is similar to our previous work in $\mathrm{Al}_{2} \mathrm{O}_{3}$ slabs [13]. In addition, we find that although the sample size changes, the crack number and the phenomenon of crack length hierarchical are relatively close at the same quenching temperature difference, as shown in Fig. 3 and Table 2.

Fig. 4 shows the crack evolution process of specimens with different sizes under different temperature differences by numerical simulation. It can be seen that the number of cracks increases with the increase of temperature difference, while the number of cracks varies little with size, as shown in Table 2. This is consistent with the experimental results.

We can explain the crack spacing remain size-independent by the 

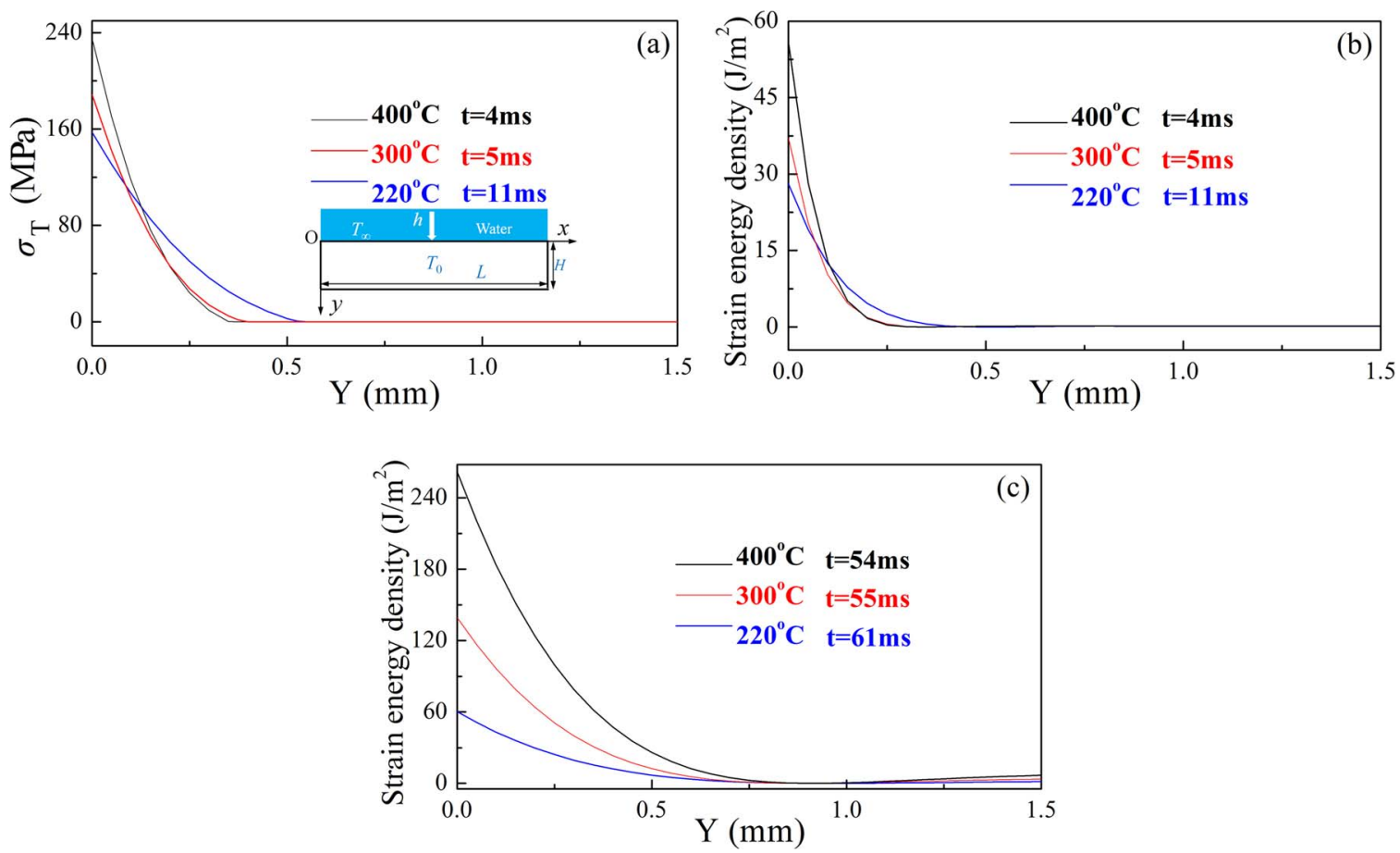

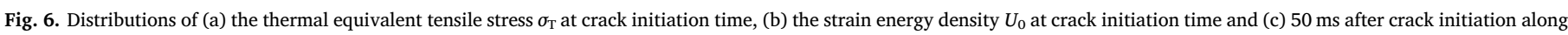
$y$-direction at different temperature differences for $10 \mathrm{~mm}$ wide ceramic.

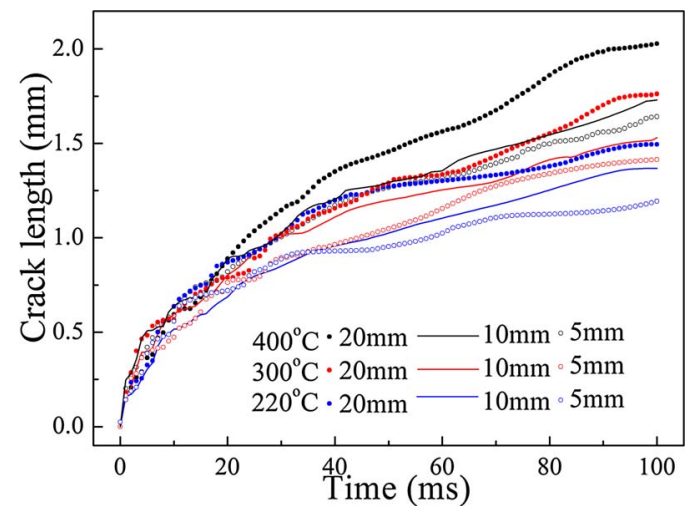

Fig. 7. Crack propagation diagram in different size ceramics under thermal shock at different temperature differences.

distribution of thermal stress and strain energy at crack initiation time. Taking $300{ }^{\circ} \mathrm{C}$ as an example, the time of crack initiation in different size ceramics is about $t=5 \mathrm{~ms}$ after the surface in contact with water in the present experiment and calculation. The decisive stress is the equivalent tensile stress $\sigma_{\mathrm{T}}$. Assuming no crack appears at $t=5 \mathrm{~ms}$ and ceramic is mesoscopic homogeneity, the distributions of $\sigma_{\mathrm{T}}$ and the strain energy density $U_{0}$ along $y$-direction (the distance from the thermal shock surface) at $T_{0}=300{ }^{\circ} \mathrm{C}$ for different width of ceramics are shown in Fig. 5. It is seen that the distributions of $\sigma_{\mathrm{T}}$ and $U_{0}$ near the surface can be regarded as size-independent in the range of 5 $\mathrm{mm} \sim 20 \mathrm{~mm}$, thus the crack spacing mainly determined by $\sigma_{\mathrm{T}}$ and $U_{0}$ can also be regarded as size-independent.

The distributions of $\sigma_{\mathrm{T}}$ and $U_{0}$ along $y$-direction for $10 \mathrm{~mm}$ wide specimen at crack initiation time for different $\Delta T$ are shown in Fig. 6. It is seen that $\sigma_{\mathrm{T}}$ and $U_{0}$ near the surface increase with the increase of $\Delta T$. This fact explains the phenomenon that the higher the $\Delta T$, the smaller the crack spacing. The results are similar to what was reported by $\mathrm{Wu}$ et al. in double-side thermal shock test of $\mathrm{Al}_{2} \mathrm{O}_{3}$ sheet [14].

Note that, we find that there are always cracks shorter than $0.2 \mathrm{~mm}$ in the calculation, and this is also the case in the Tang or Bourdin's studies $[9,10]$, but the shortest crack observed in the experimental specimen is about $0.5 \mathrm{~mm}$, as shown in Fig. 3. This slight difference may be caused by the fact that the numerical model cannot simulate every detail of the microstructure of complex brittle materials, or the numerical and experimental tests may be slightly different in terms of boundary conditions. In addition, removing the smallest cracks, the total numbers of cracks initiated in the brittle materials with different $\Delta T$ from both the numerical and experimental tests are similar to each other.

To compare the crack propagation speed, the length of the propagating cracks in different size ceramics with time at different $\Delta T$ is plotted in Fig. 7. Note that, each line is the average value of 5 cracks to avoid large error. From Fig. 7, we can see that the thermal shock cracks gradually spread with time and the growth rate starts relatively fast which is about $0.2 \mathrm{~m} / \mathrm{s}$ within a millisecond, and then it gradually slows down until it stops [12]. With the increase of water quenching temperature, the length of thermal shock crack increases more with time, that is, the average propagation speed increases with the increase of temperature difference. Taking $10 \mathrm{~mm}$ wide specimen as an example, the average speed is from about $13.7 \mathrm{~mm} / \mathrm{s}$ of $220^{\circ} \mathrm{C}$ to about $17.3 \mathrm{~mm} / \mathrm{s}$ of $400{ }^{\circ} \mathrm{C}$ within $100 \mathrm{~ms}$, which has an increase of $26.4 \%$. In cases of $5 \mathrm{~mm}$ and $20 \mathrm{~mm}$, the increased values are $37.5 \%$ and $35.6 \%$, respectively, as shown in Table 2 . In addition, we find that the average speed of thermal shock crack also increases with the increase of specimen size. Taking $\Delta T=300{ }^{\circ} \mathrm{C}$ as an example, the average speed is from about $14.1 \mathrm{~mm} / \mathrm{s}$ of $5 \mathrm{~mm}$ to about $17.6 \mathrm{~mm} / \mathrm{s}$ of $20 \mathrm{~mm}$, which has an increase of $24.6 \%$ within $100 \mathrm{~ms}$. In cases of $\Delta T=220^{\circ} \mathrm{C}$ and $\Delta T=400{ }^{\circ} \mathrm{C}$, the increased values are $25.3 \%$ and $23.5 \%$, respectively, as shown in Table 2. As a result, the proportional increase of sample size does not make the crack propagation speed proportional increase, although the thermal shock crack length will proportional increase with the specimen width after thermal shock [14], the possible reason is that the crack propagation time is longer in large specimens. Therefore, the effect of the increase of quenching temperature difference on the crack propagation speed is greater than the increase of specimen size.

The calculated crack length with time and the comparison with the experimental result at different temperature differences are shown in 

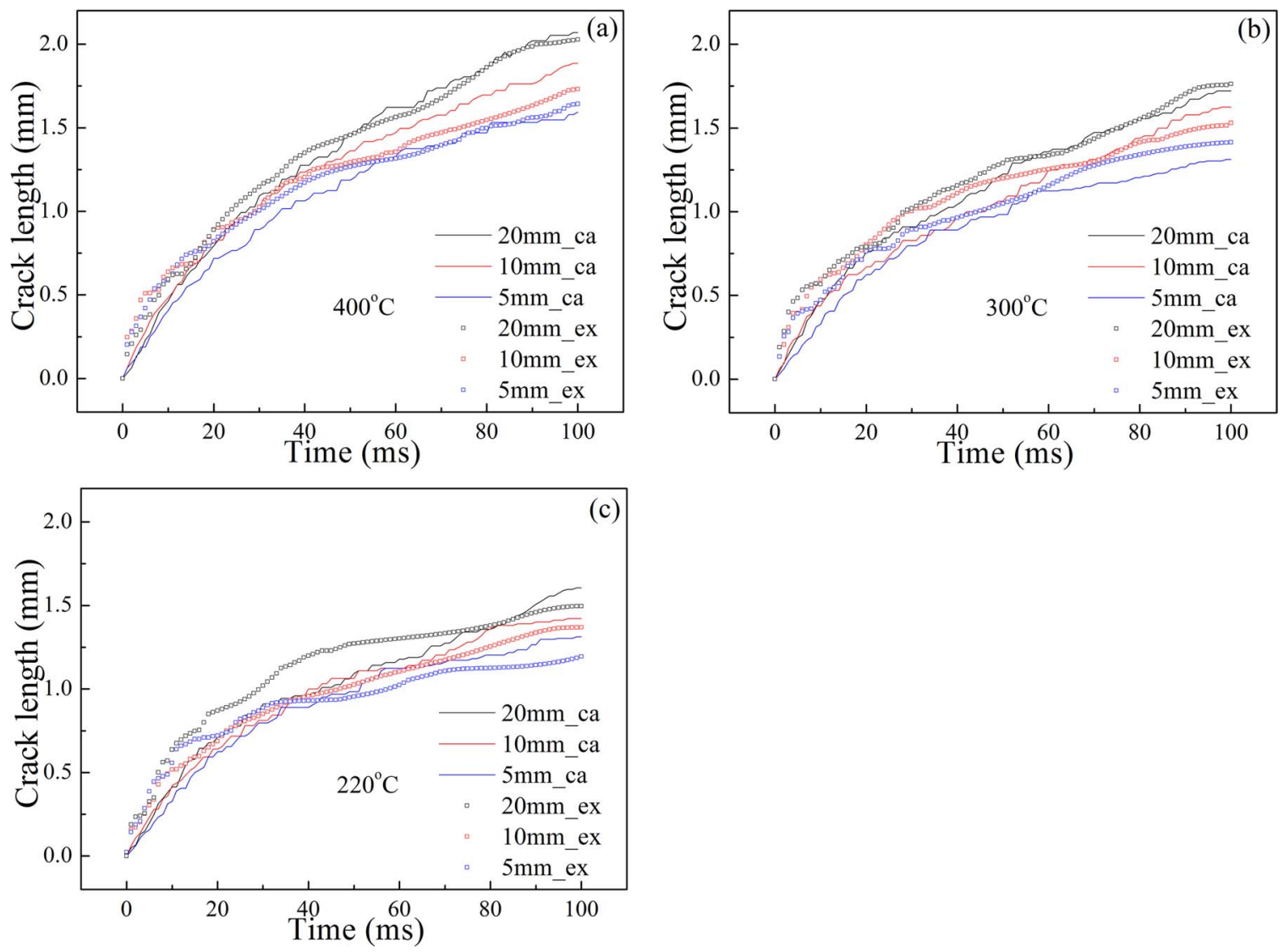

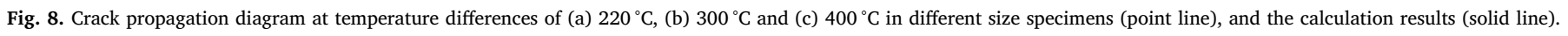

Fig. 8. The calculated results are in good agreement with the experimental results, that is, the crack propagation speed increases with the increase of quenching temperature difference or specimen size.

We can use the distribution of strain energy to explain why the increase of sample size causes the increase of crack propagation speed. In the case of $300{ }^{\circ} \mathrm{C}$, the specimens of different size produce cracks with similar spacing at crack initiation time. As time goes on, assuming no crack appears at $t=55 \mathrm{~ms}$, the strain energy of the crack area increases with specimen size, as shown in Fig. 5c. Therefore, the more strain energy, the more quickly crack propagation speed is. In addition, we can see that the increase of strain energy with temperature difference is more than that with size, as shown in Fig. 6c. More strain energy makes the crack propagation speed increase, even when the number of cracks increases.

Further, there are still some deviations between the calculated and experimental speeds in Fig. 8. In this study, the surface heat transfer coefficient used in the calculation is considered as a constant value. The effect of heat transfer coefficient on crack propagation is also calculated, and it is found that the crack propagation speed increases with the increase of heat transfer coefficient. However, the surface heat transfer coefficient largely depends not only on the initial quenching temperature but also on its evolution in quenching media $[15,16]$, which affects the crack propagation speed.

\section{Conclusions}

Real-time thermal shock tests of ceramic show that the increases in size and thermal shock temperature difference make the thermal shock crack propagation speed increase. Comparing to the size, the temperature difference has a greater influence on the crack growth rate of ceramic. The meso-damage mechanics is utilized to simulate the thermal shock crack growth, and the calculated results are consistent with the experimental observations. As a result, the meso-damage mechanics which used to study the final phenomenon of thermal shock crack, is also a good method to predict the crack propagation speed of thermal shock crack.

\section{Acknowledgments}

This work was supported by the National Natural Science Foundations of China (grant. 11572326 and 11472285), and the Strategic Priority Research Program of the Chinese Academy of Sciences (Grant No. XDB22040102).

\section{References}

[1] H.A. Bahr, G. Fischer, H.J. Weiss, Thermal-shock crack patterns explained by single and multiple crack propagation, J. Mater. Sci. 21 (8) (1986) 2716-2720.

[2] W.E. Pompe, Thermal shock behavior of ceramic materials-modeling and measurement, in: G.A. Schneider, G. Petzow (Eds.), Thermal Shock and Thermal Fatigue Behavior of Advanced Ceramics, 1993.

[3] R. Danzer, T. Lube, P. Supancic, R. Damani, Fracture of ceramics, Adv. Eng. Mater. 10 (2008) 275-298.

[4] Z.P. Bazant, H. Ohtsubo, K. Aoh, Stability and post-critical growth of a system of cooling or shrinkage cracks, Int. J. Fract. 15 (5) (1979) 443-456.

[5] H.A. Bahr, H.J. Weiss, H.G. Maschke, F. Meissner, Multiple crack propagation in a strip caused by thermal shock, Theor. Appl. Fract. Mech. 10 (3) (1988) 219-226.

[6] D.R. Jenkins, Optimal spacing and penetration of cracks in a shrinking slab, Phys. Rev. E 71 (5) (2005) 056117.

[7] C.P. Jiang, X.F. Wu, J. Li, F. Song, Y.F. Shao, X.H. Xu, P. Yan, A study of the mechanism of formation and numerical simulations of crack patterns in ceramics subjected to thermal shock, Acta. Mater. 60 (11) (2012) 4540-4550.

[8] J. Li, F. Song, C.P. Jiang, Direct numerical simulations on crack formation in ceramic materials under thermal shock by using a non-local fracture model, J. Eur. Ceram. Soc. 33 (13-14) (2013) 2677-2687.

[9] S.B. Tang, H. Zhang, C.A. Tang, H.Y. Liu, Numerical model for the cracking behavior of heterogeneous brittle solids subjected to thermal shock, Int. J. Solids Struct. 80 (2016) 520-531.

[10] B. Bourdin, J.J. Marigo, C. Maurini, P. Sicsic, Morphogenesis and propagation of complex cracks induced by thermal shocks, Phys. Rev. Lett. 112 (2014) 014301. 
[11] P. Sicsic, J.J. Marigo, C. Maurini, Initiation of a periodic array of cracks in the thermal shock problem: a gradient damage modeling, J. Mech. Phys. Solids 63 (2) (2014) 256-284.

[12] Y.F. Shao, F. Song, B.Y. Liu, W. Li, L. Li, C.P. Jiang, Observation of ceramic cracking during quenching, J. Am. Ceram. Soc. 100 (2017) 520-523.

[13] Y.F. Shao, X.H. Xu, S.H. Meng, G.H. Bai, C.P. Jiang, F. Song, Crack patterns in ceramic plates after quenching, J. Am. Ceram. Soc. 93 (2010) 3006-3008.

[14] X.F. Wu, C.P. Jiang, F. Song, J. Li, Y.F. Shao, X.H. Xu, P. Yan, Size effect of thermal shock crack patterns in ceramics and numerical predictions, J. Eur. Ceram. Soc. 35 (2015) 1263-1271.

[15] P.F. Becher, Effect of water bath temperature on the thermal shock of $\mathrm{Al}_{2} \mathrm{O}_{3}, \mathrm{~J}$. Am. Ceram. Soc. 64 (1981) C17-C18.

[16] Z.L. Zhou, F. Song, Y.F. Shao, S.H. Meng, C.P. Jiang, J. Li, Characteristics of the surface heat transfer coefficient for $\mathrm{Al}_{2} \mathrm{O}_{3}$ ceramic in water quench, J. Eur. Ceram. Soc. 32 (2012) 3029-3034. 